\title{
Impact of lymph node density on prognosis of advanced laryngeal carcinoma with nodal metastasis
}

\section{Original Article}

\author{
Mena E. Abdelmalek, Aly Ahmed El-Garem, Ahmed El-Farouk Abd El-Fattah, \\ Sameh M. Zamzam
}

Department of Otolaryngology, Faculty of Medicine, Cairo University, Cairo, Egypt.

\begin{abstract}
Objective: To determine the prognostic value of lymph node density (LND) as a predictor for tumor recurrence in patients with advanced laryngeal carcinoma undergoing curative surgery.

Patients and Methods: This is a prospective study, included 87 patients, diagnosed with locally advanced laryngeal carcinoma (T3 \& T4a) and carried out total laryngectomy with neck dissection, presented to otorhinolaryngology outpatient clinic at faculty of medicine, Cairo university, Egypt, between June 2018 and May 2019. LND was determined by calculating the ratio between number of resected lymph nodes (LNs) positive for malignancy and total number of resected LNs. The mean follow up duration for tumor recurrence was 24 months (range 17 - 29 months).

Results: LND, number of positive LNs, involved surgical margins, presence of metastatic LNs and adjuvant chemoradiation were statistically significant predictors for disease recurrence in univariate analysis. LND was the only independent predictor of recurrence in pathologically positive neck node $(\mathrm{pN}+)$ patients in multivariate analysis. In patients with LND $>0.066$, hazard ratio for disease recurrence was $3.887(P=0.021)$, and for nodal recurrence was $6.453(P=0.008)$, reaching LND $>0.25$ significantly increased hazard ratio for recurrence to $5.838(P=0.001)$, and for nodal recurrence to $9.329(P=0.001)$ compared with pN0 cases.

Conclusion: LND was found to be the only independent predictor for disease recurrence in pN+ laryngeal cancer. LND should be used complementary to the conventional TNM staging to assess the precise risk of treatment failure and planning of possible postoperative adjuvant treatment.
\end{abstract}

Key Words: Laryngeal carcinoma, laryngectomy, lymph node density, prognostic factors, recurrence.

Received: 8 January 2021, Accepted: 16 January 2021

Corresponding Author: Mena Esmat Abdelmalek, MD, Department of Otorhinolaryngology, Faculty of Medicine, Cairo University, Egypt, Tel.: 01002827489, E-mail: mena.esmat@kasralainy.edu.eg

ISSN: 2090-0740, 2021 Vol.22

\section{INTRODUCTION}

Head \& neck cancers account for 3-7 \% of malignancies. Laryngeal squamous cell carcinoma (SCC) is among the most common head \& neck cancers, representing about $1-2 \%$ of all body cancers and is the 2 nd most common cancer of the respiratory tract following lung carcinoma ${ }^{[1]}$.

The prognosis of laryngeal SCC after laryngectomy is commonly assessed by presence of LN metastasis, pTNM stage, site of origin and resection margins ${ }^{[2]}$. Recently, LND has emerged as a prognostic factor for laryngeal cancer ${ }^{[3-7]}$. LND is defined as the ratio of number of positive LNs to the total number of resected LNs. Follow up for tumor recurrence is most important in the first 2 years postoperatively and is generally valuable for 5 years postoperatively. $50 \%$ of tumor recurrence after laryngectomy occurs during the first 8.8 months, more than $60 \%$ within the first year and more than $90 \%$ occurs within the first 2 years ${ }^{[8]}$.
We prospectively evaluated LND in patients with advanced laryngeal cancer undergoing curative surgery and investigated its relation to tumor recurrence.

\section{PATIENTS AND METHODS:}

\subsection{Patients selection}

We prospectively investigated 104 patients, newly diagnosed with locally advanced laryngeal SCC (T3, T4a) and candidate for total laryngectomy with either comprehensive or selective neck dissection, presented to otorhinolaryngology department, Cairo university, Egypt; which is a tertiary multidisciplinary referral center for advanced otolaryngologic surgeries, in the period from June 2018 to May 2019. 87 patients were included in this study. Exclusion criteria were: Patients refusing or unfit for surgery $(n=2)$, non SCC of the larynx $(n=1)$, patients with distant metastasis $(n=1)$, previous treatment including 
radiotherapy, chemoradiation or partial laryngeal surgery $(n=3)$, patients amenable for partial laryngeal surgery $(n=2)$, nodal yield $<6$ for unilateral selective neck dissection and $<10$ for unilateral radical neck dissection $(n=5)$ and missed follow up before 12 months postoperatively $(n=3)$. Written consent for all patients was obtained after full explanation of the operation and other alternatives. Patients demographic \& clinicopathologic data, treatment and follow up details were recorded.

\subsection{Treatment}

All included patients underwent total laryngectomy. In addition, patients with clinically N0 neck had selective neck dissection for levels II-IV. Patients with $\mathrm{N}+$ ve neck had comprehensive neck dissection. Cases with supraglottic \& transglottic involvement or contralateral suspicious nodes had bilateral neck dissections. Specimens were excised en bloc.

Adjuvant radiotherapy was administered to patients with nodal metastasis, close surgical margins and extralaryngeal tumor invasion with free surgical margins. While adjuvant chemoradiation was given for tumors with pathologic risk factors including positive surgical margins or LN metastasis with extracapsular extension. Adjuvant treatment typically started 6 to 8 weeks after surgery.

\subsection{Follow up}

The mean follow up duration was 24 months (range 17-29 months). The outcome measures included any form of tumor recurrence within the follow up period. Follow up period was measured from the date of surgery until the last follow up visit or death. Follow up for tumor recurrence was done every 3 months. Follow up visits included detailed history taking, and full head and neck examination. For any suspected locoregional or distant recurrence, imaging and/or pathological sampling in the form of FNAC/histopathological examination from suspicious lesions were performed as needed.

\subsection{Statistical analysis}

LND was determined by calculating the ratio between number of excised malignant LNs and total number of excised LNs, regardless whether unilateral or bilateral neck dissection was performed.

Predictors of tumor recurrence were determined using Cox regression analysis to calculate their hazard ratios (HRs) $\& 95 \%$ confidence intervals. The main potential predictors of recurrence that were evaluated are LND, number of +ve resected LNs for malignancy and pathologic $\mathrm{N}$ stage. Other factors were evaluated including age, sex, histologic grade, pathologic $\mathrm{T}$ stage, surgical margins, nodal extracapsular extension and adjuvant treatment. Statistically significant factors associated with tumor recurrence in the univariate analysis were further submitted to multivariate regression analysis through the Cox regression model to estimate independent prognostic factors.

LNR was measured as a continuous variable. Furtherly, we proceeded to determine the most appropriate cut off point for categorizing LNR to high and low risk groups. ROC (Receiver Operating Characteristic) curve was used to estimate best cut off value of LN density for detection of recurrence rate using the area under the ROC curve as criteria. This calculation showed that the best cut off value for LND was 0.066 (area under the curve $0.668 ; 95 \%$ confidence interval $0.533-0.803$ ) (Figure 1).

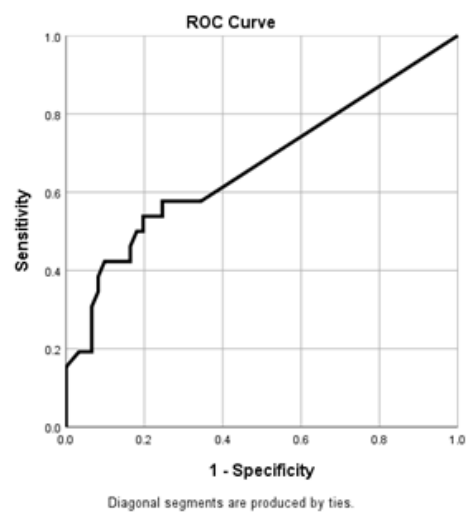

Fig 1: ROC curve for detection of recurrence using LND

For data analysis, SPSS program version 26 was used (IBM Corp., Armonk, NY, USA). We used mean, standard deviation, minimum, maximum \& median to describe quantitative data, and frequency $\&$ percentage for categorical data. The non-parametric Mann-Whitney test was used to compare quantitative variables. To compare categorical data, Chi square $(\chi 2)$ test was performed. $P$-values $<0.05$ were considered statistically significant.

\section{RESULTS:}

\subsection{Clinicopathologic and treatment characteristics}

The study included 87 patients, 84 males \& 3 females, mean age was 59 years (range $36-83$ years), the mean follow up duration was 24 months (range $17-29$ months). (Table 1) Summarizes clinicopathologic and treatment characteristics of the study group and their relation to tumor recurrence. 
Table 1: Summary of clinicopathologic and treatment characteristics and their relation to tumor recurrence: A-Categorical factors, B-Quantitative factors.

\begin{tabular}{|c|c|c|c|c|c|c|c|c|}
\hline & & \multirow{2}{*}{\multicolumn{2}{|c|}{ Whole study }} & \multicolumn{4}{|c|}{ Recurrence } & \multirow{3}{*}{$P$ value } \\
\hline & & & & \multicolumn{2}{|c|}{ yes } & \multicolumn{2}{|c|}{ no } & \\
\hline & & Count & $\%$ & Count & $\%$ & Count & $\%$ & \\
\hline \multirow[t]{2}{*}{ Sex } & Male & 84 & 96.6 & 25 & $29.8 \%$ & 59 & $70.2 \%$ & \\
\hline & Female & 3 & 3.4 & 1 & $33.3 \%$ & 2 & $66.7 \%$ & \\
\hline \multirow[t]{2}{*}{ Type of ND } & Selective & 61 & $70.1 \%$ & 18 & $29.5 \%$ & 43 & $70.5 \%$ & \\
\hline & Comprehensive & 26 & $29.9 \%$ & 9 & $30.8 \%$ & 18 & $69.2 \%$ & 0.300 \\
\hline \multirow[t]{2}{*}{ Contralateral ND } & Selective & 40 & $46.0 \%$ & 12 & $30.0 \%$ & 28 & $70.0 \%$ & \\
\hline & No & 47 & $54.0 \%$ & 14 & $29.8 \%$ & 33 & $70.2 \%$ & 0.983 \\
\hline \multirow[t]{2}{*}{ Lymph nodes } & $+\mathrm{ve}$ & 36 & $41.4 \%$ & 15 & $41.7 \%$ & 21 & $58.3 \%$ & \\
\hline & -ve & 51 & $58.6 \%$ & 11 & $21.6 \%$ & 40 & $78.4 \%$ & $\underline{0.044}$ \\
\hline \multirow[t]{2}{*}{ pT stage } & 3 & 32 & $36.8 \%$ & 8 & $25.0 \%$ & 24 & $75.0 \%$ & \\
\hline & $4 a$ & 55 & $63.2 \%$ & 18 & $32.7 \%$ & 37 & $67.3 \%$ & 0.448 \\
\hline \multirow[t]{5}{*}{$\mathrm{pN}$ stage } & 0 & 51 & $58.6 \%$ & 11 & $21.6 \%$ & 40 & $78.4 \%$ & \\
\hline & 1 & 10 & $11.5 \%$ & 3 & $30.0 \%$ & 7 & $70.0 \%$ & \\
\hline & $2 \mathrm{a}$ & 5 & $5.7 \%$ & 2 & $40.0 \%$ & 3 & $60.0 \%$ & 0.213 \\
\hline & $2 b$ & 10 & $11.5 \%$ & 4 & $40.0 \%$ & 6 & $60.0 \%$ & \\
\hline & $2 \mathrm{c}$ & 11 & $12.6 \%$ & 6 & $54.5 \%$ & 5 & $45.5 \%$ & \\
\hline \multirow{3}{*}{$\begin{array}{l}\text { Histological grade } \\
\text { (differentiation) }\end{array}$} & Well & 4 & $4.6 \%$ & 1 & $25.0 \%$ & 3 & $75.0 \%$ & \\
\hline & Poor & 9 & $10.3 \%$ & 4 & $44.4 \%$ & 5 & $55.6 \%$ & 0.689 \\
\hline & Moderate & 74 & $85.1 \%$ & 21 & $28.4 \%$ & 53 & $71.6 \%$ & \\
\hline \multirow[t]{3}{*}{ Margins } & Positive & 4 & $4.6 \%$ & 3 & $75.0 \%$ & 1 & $25.0 \%$ & \\
\hline & Close & 1 & $1.1 \%$ & 1 & $100.0 \%$ & 0 & $0.0 \%$ & $\underline{0.026}$ \\
\hline & Negative & 82 & $94.3 \%$ & 22 & $26.8 \%$ & 60 & $73.2 \%$ & \\
\hline \multirow{2}{*}{$\begin{array}{c}\text { Extracapsular } \\
\text { extension }\end{array}$} & Positive & 3 & $3.4 \%$ & 2 & $66.7 \%$ & 1 & $33.3 \%$ & \\
\hline & Negative & 84 & $96.6 \%$ & 24 & $28.6 \%$ & 60 & $71.4 \%$ & \\
\hline
\end{tabular}




\begin{tabular}{ccccccccc} 
Adjuvant RT & Yes & 75 & $86.2 \%$ & 23 & $30.7 \%$ & 52 & $69.3 \%$ & \\
& No & 12 & $13.8 \%$ & 3 & $25.0 \%$ & 9 & $75.0 \%$ \\
$\begin{array}{c}\text { Adjuvant } \\
\text { Chemoradiation }\end{array}$ & Yes & 8 & $9.2 \%$ & 7 & $63.6 \%$ & 4 & $36.4 \%$ & $\underline{\mathbf{0 . 0 1 4}}$ \\
LND & No & 79 & $90.8 \%$ & 19 & $25.0 \%$ & 57 & $75.0 \%$ & $80.3 \%$ \\
& $<0.066$ & 61 & $70.1 \%$ & 12 & $19.7 \%$ & 49 & $\underline{\mathbf{0 . 0 0 1}}$ \\
& $>0.066$ & 26 & $29.9 \%$ & 14 & $53.8 \%$ & 12 & $46.2 \%$ & \\
\hline
\end{tabular}

(A)

\begin{tabular}{|c|c|c|c|c|c|c|c|c|c|c|c|}
\hline & \multicolumn{10}{|c|}{ Recurrence } & \multirow{3}{*}{$\begin{array}{c}P \\
\text { value }\end{array}$} \\
\hline & \multicolumn{5}{|c|}{ Yes } & \multicolumn{5}{|c|}{ No } & \\
\hline & Mean & SD & Median & Min & Max & Mean & SD & Median & Min & Max & \\
\hline Age & 59.04 & 10.88 & 57.50 & 36.00 & 82.00 & 59.08 & 9.50 & 60.00 & 40.00 & 83.00 & 0.738 \\
\hline No of LNs & 19.81 & 10.83 & 15.50 & 7.00 & 45.00 & 21.10 & 9.93 & 19.00 & 10.00 & 54.00 & 0.358 \\
\hline $\begin{array}{c}\text { No of }+ \text { ve } \\
\text { LNs }\end{array}$ & 2.62 & 3.42 & 1.00 & 0.00 & 10.00 & 0.87 & 1.63 & 0.00 & 0.00 & 7.00 & $\underline{0.012}$ \\
\hline $\begin{array}{c}\text { LND in } \\
\mathrm{pN}+\text { cases }\end{array}$ & 23.57 & 18.79 & 18.75 & 4.44 & 66.67 & 10.78 & 8.31 & 9.09 & 2.38 & 28.57 & $\underline{0.007}$ \\
\hline
\end{tabular}

(B)

\subsection{Recurrence}

Among all study group, recurrence occurred in 26 patients out of $87(29.89 \%)$. Among the 51 patients with pathologically negative $\mathrm{LN}$ for malignancy $(\mathrm{pN}-)$, tumor recurrence was observed in 11 patients $(21.57 \%)$ while among the $36 \mathrm{pN}+$ patients, tumor recurrence was observed in 15 patients (41.67\%). Locoregional recurrence occurred in 25 patients: local in 9, regional in 10, and both local and regional recurrence in 6 . Distant lung metastases occurred in 2 patients, one of them alone while the other in addition to nodal recurrence. Figures $2 \& 3$ show samples of locoregional recurrence detected on imaging.

Fig 2: 2 CT neck studies (A \& B) done at radiology department, Cairo University hospital showing local recurrence after laryngectomy with neck dissection for laryngeal SCC

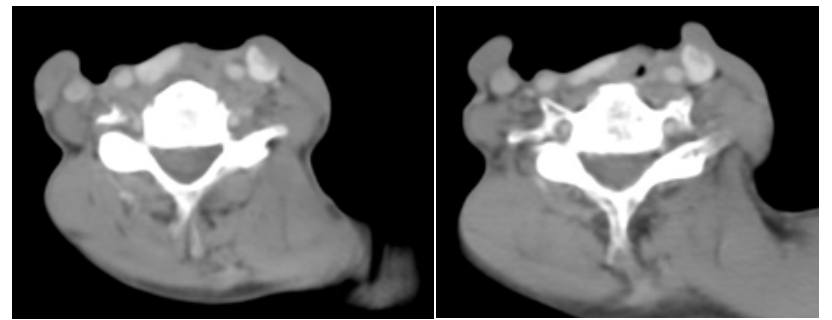

(A)

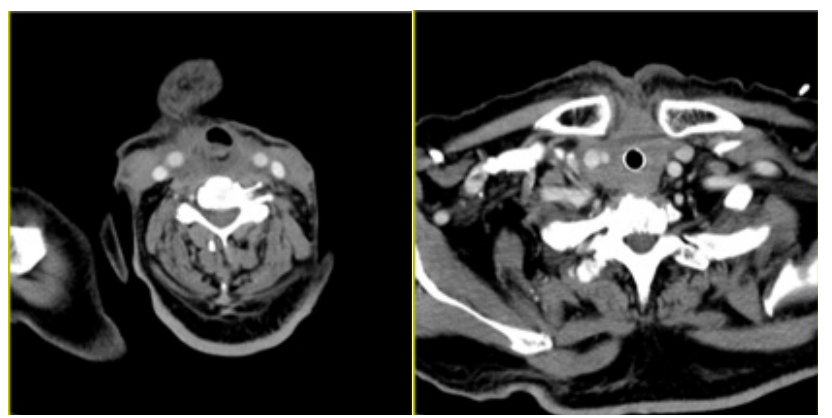

(B) 
Fig 3: 2 CT neck studies (A \& B) done at radiology department, Cairo University hospital showing nodal recurrence after laryngectomy with neck dissection for laryngeal SCC
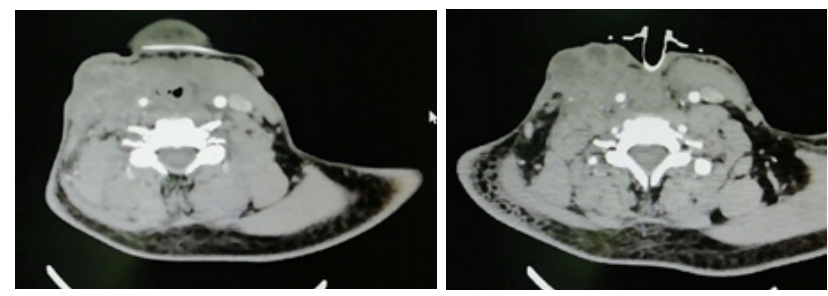

(A)
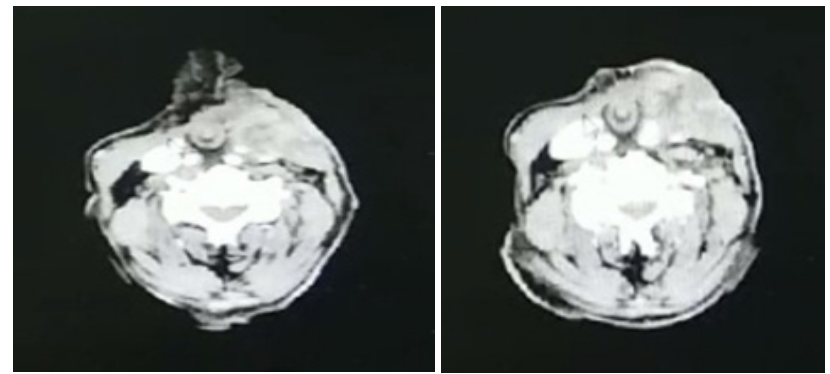

(B)

\subsection{Predictors of treatment failure}

The univariate analysis revealed that LND, number of positive LNs, involved surgical margins, presence of metastatic LNs and adjuvant chemoradiation were statistically significant predictors for disease recurrence. Incidence of disease recurrence was significantly higher in patients receiving adjuvant chemoradiation, however this is most probably because adjuvant chemoradiation was given only to patients with other poor prognostic factors. The relation between different treatment and pathologic factors and tumor recurrence is summarized in (Table 1).

To further evaluate the impact of prognostic variables, the prognostic variables significantly associated with recurrence in the univariate analysis were included in a forward stepwise Cox regression analysis to detect independent predictors of recurrence. LND, number of positive LNs, positive surgical margins and adjuvant chemotherapy were significantly associated with disease recurrence in univariate analysis and were included in the multivariate Cox regression analysis. It revealed that LND $>0.066$ remained the only significant independent factor for overall disease recurrence (HR 3.887, CI: $1.23-$ $12.29, P=0.021$ ) (Table 2). Similarly, LND $>0.066$ was the only significant independent factor for nodal recurrence (HR 6.453, CI: $1.625-25.625, P=0.008$ ).

Table 2: Univariate and multivariate Cox regression analysis to identify independent predictors for recurrence

\begin{tabular}{|c|c|c|c|c|c|c|c|c|}
\hline \multirow{4}{*}{ Recurrence } & \multicolumn{4}{|c|}{ Univariate } & \multicolumn{4}{|c|}{ Multivariate } \\
\hline & \multirow{3}{*}{$P$ value } & \multirow{3}{*}{ HR } & \multirow{2}{*}{\multicolumn{2}{|c|}{$95 \% \mathrm{CI}$}} & \multirow{3}{*}{$P$ value } & \multirow{3}{*}{ HR } & \multicolumn{2}{|c|}{$95 \% \mathrm{CI}$} \\
\hline & & & & & & & & \\
\hline & & & Lower & Upper & & & Lower & Upper \\
\hline LND $>0.066$ & $\underline{0.001}$ & 3.657 & 1.685 & 7.933 & $\underline{0.021}$ & 3.887 & 1.230 & 12.288 \\
\hline Adjuvant CTH & $\underline{0.008}$ & 3.232 & 1.354 & 7.717 & 0.238 & 2.107 & 0.612 & 7.258 \\
\hline No. of + ve LNs & $\underline{0.002}$ & 1.204 & 1.072 & 1.354 & 0.993 & 0.999 & 0.827 & 1.207 \\
\hline \multirow{2}{*}{ Margins } & $\underline{0.008}$ & 5.239 & 1.542 & 17.804 & 0.243 & 2.652 & 0.515 & 13.656 \\
\hline & 0.228 & 3.438 & 0.462 & 25.558 & 0.358 & 2.969 & 0.292 & 30.230 \\
\hline
\end{tabular}




\subsection{Impact of lymph node density}

Regarding $\mathrm{pN}+$ patients, LND was statistically significant predictor of overall treatment failure and nodal recurrence, however had no significant relation with local recurrence alone. Mean LND in $\mathrm{pN}+$ patients with disease recurrence was 0.236 , while in patients without disease recurrence was $0.108(P=0.007)$. Similarly mean LND in $\mathrm{pN}+$ patients with nodal recurrence was 0.264 , while in patients without nodal recurrence was $0.116(P=0.009)$. However mean LND in $\mathrm{pN}+$ patients with local recurrence alone was 0.159 compared to 0.162 in the rest of patients, showing no significant relation between LND and local recurrence alone.

The $\mathrm{pN}+$ patients were then categorized into two groups, with LND $<0.066$ and LND $>0.066$, using ROC curve. Figure 4 shows incidence of recurrence with LND $>$ 0.066 versus $<0.066$.
Fig 4: Incidence of recurrence with LND above and below 0.066
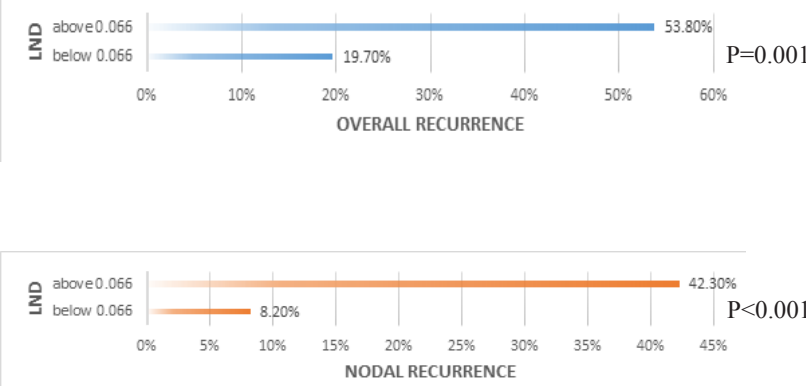

More increase in LND had led to increased incidence of overall recurrence and more obviously nodal recurrence. Regarding overall recurrence, reaching LND $>0.25$ significantly increased HR to $5.838(P=0.001)$ compared with $\mathrm{pN} 0$ cases. Regarding nodal recurrence, LND of 0.15 0.25 significantly increased HR to $5.065(P=0.026)$ and LND $>0.25$ significantly increased HR to $9.329(P=0.001)$ (Table 3).

Table 3: Incidence overall recurrence \& nodal recurrence with increasing LND

\begin{tabular}{|c|c|c|c|c|c|c|c|c|c|}
\hline & \multirow{2}{*}{ LND } & \multicolumn{2}{|c|}{ Recurrence } & \multicolumn{2}{|c|}{ No recurrence } & \multirow{2}{*}{ Pvalue } & \multirow{2}{*}{ HR } & \multicolumn{2}{|c|}{$95 \% \mathrm{CI}$} \\
\hline & & Count & $\%$ & Count & $\%$ & & & Lower & Upper \\
\hline \multirow{5}{*}{$\begin{array}{l}\text { Overall } \\
\text { recurrence }\end{array}$} & 0 & 11 & $21.6 \%$ & 40 & $78.4 \%$ & \multicolumn{4}{|c|}{ Reference } \\
\hline & $>0-0.05$ & 1 & $12.5 \%$ & 7 & $87.5 \%$ & 0.564 & 0.548 & 0.071 & 4.242 \\
\hline & $0.05-0.15$ & 5 & $35.7 \%$ & 9 & $64.3 \%$ & 0.211 & 1.966 & 0.683 & 5.660 \\
\hline & $0.15-0.25$ & 4 & $57.1 \%$ & 3 & $42.9 \%$ & 0.053 & 3.093 & 0.984 & 9.720 \\
\hline & $>0.25$ & 5 & $71.4 \%$ & 2 & $28.6 \%$ & $\underline{0.001}$ & 5.838 & 1.996 & 17.069 \\
\hline \multirow{2}{*}{$\begin{array}{l}\text { Nodal } \\
\text { recurrence }\end{array}$} & 0 & 5 & $9.8 \%$ & 46 & $90.2 \%$ & \multicolumn{4}{|c|}{ Reference } \\
\hline & $>0-0.05$ & 0 & $0.0 \%$ & 8 & $100.0 \%$ & 0.984 & 0.000 & 0.000 & 0.000 \\
\hline & $0.05-0.15$ & 4 & $28.6 \%$ & 10 & $71.4 \%$ & 0.069 & 3.384 & 0.908 & 12.611 \\
\hline & $0.15-0.25$ & 3 & $42.9 \%$ & 4 & $57.1 \%$ & $\underline{0.026}$ & 5.065 & 1.209 & 21.220 \\
\hline & $>0.25$ & 4 & $57.1 \%$ & 3 & $42.9 \%$ & $\underline{0.001}$ & 9.329 & 2.458 & 35.412 \\
\hline
\end{tabular}




\section{DISCUSSION}

Treatment of advanced laryngeal SCC (T3, T4a) involves either total laryngectomy with elective or therapeutic neck dissection, or concurrent chemoradiation aiming for organ preservation especially if laryngeal cartilage is not invaded to the surrounding tissues with low tumor load. Curative surgery remains the gold standard of care for advanced laryngeal carcinoma in our institution; faculty of medicine, Cairo University. This is mainly due to the limitations in the efficacy of chemoradiation in locally advanced cases with invasion of laryngeal skeleton, which unfortunately constitute majority of presenting cases at our community. In addition to complications of chemotherapy limiting its use in elderly patients. Moreover, Salvage surgery is the only option for curative treatment after failure of chemoradiation ${ }^{[9,10]}$.

In this study, incidence of disease recurrence in $\mathrm{pN}+$ patients was $41.7 \%$, which is nearly double that in pN0 patients which was $21.6 \%$, difference was statistically significant $(P=0.044)$. This agrees with the previous studies that presence of LN metastasis worsens prognosis by about $50 \%$. However, with metastatic cervical LNs, pathologic nodal stage does not necessarily predict prognosis. Recently, LND has emerged as possible prognostic factor in $\mathrm{pN}+$ laryngeal cancer, which may be have an important impact on adjuvant treatment decision ${ }^{[11-13]}$.

Five previous studies discussed impact of LND on prognosis of $\mathrm{pN}+$ laryngeal cancer. (Table 4) Shows brief summary for results of previous studies discussing impact of LND on prognosis of laryngeal cancer ${ }^{[3-7]}$. Our results agree with most of the previous studies that LND is an independent prognostic factor in laryngeal cancer with nodal metastasis, and advocates its use complementary to the conventional TNM staging. Only Kunzel et al suggested that LND seems to have limited role in deciding adjuvant treatment in laryngeal cancer patients in comparison with other locations, \& prospective trials are needed to be able to offer evidence based recommendations for adjuvant treatment based on the LND. Nearly all previous studies were retrospective, which was stated in most of them to lead to potential bias and pointed to the need for future prospective studies. To our knowledge, our study is the first prospective study to assess impact of LND on prognosis of $\mathrm{pN}+$ laryngeal cancer.

Table 4: Brief summary for results of previous studies discussing impact of LND on prognosis of laryngeal cancer

\begin{tabular}{|c|c|c|c|c|c|}
\hline Study & Design & No of cases & $\begin{array}{l}\text { Outcome } \\
\text { measures }\end{array}$ & $\begin{array}{l}\text { Significant factors } \\
\text { Univariate analysis }\end{array}$ & Multivariate analysis \\
\hline Ryu et al., 2014 & Retrospective & $\begin{array}{l}\text { Total: } 156 \\
\mathrm{~N}+: 71\end{array}$ & $\begin{array}{l}\text { Cancer specific } \\
\text { mortality }\end{array}$ & $\begin{array}{l}\text { *LND } \\
* \text { No of +ve LNs } \\
* \text { Extralaryngeal spread }\end{array}$ & $\begin{array}{l}* \text { LND only, } \\
\text { cut off } 0.044\end{array}$ \\
\hline Wang et al., 2014 & $\begin{array}{l}\text { Prospective } \\
\text { part }\end{array}$ & $\begin{array}{l}\text { Reviewed } \mathrm{N}+\text { cases } \\
\text { only: } 1963 \text { from } \\
\text { SEER database }\end{array}$ & $\begin{array}{l}\text { Cause } \\
\text { specific } \\
\text { survival }\end{array}$ & $\begin{array}{l}\text { *LND } \\
\text { *TNM classification } \\
\text { *Age } \\
\text { *Black race } \\
\text { *Primary site } \\
\text { *Histological grade }\end{array}$ & $\begin{array}{l}* \text { LND, } 2 \text { cut offs: } 0.09 \text {, } \\
0.20 \\
* \text { TNM } \\
\text { classification } \\
* \text { Age } \\
* \text { Black race }\end{array}$ \\
\hline Kunzel et al., 2015 & Retropective & $\begin{array}{l}\text { Reviewed } \\
\mathrm{N}+\text { cases } \\
\text { only: } 202\end{array}$ & $\begin{array}{l}\text { OS } \\
\text { DFS }\end{array}$ & $\begin{array}{l}* \mathrm{LND} \\
* \mathrm{pT} \\
* \mathrm{pN} \\
* \text { Extracapsular extension }\end{array}$ & $\begin{array}{l}* \mathrm{pN} \\
* \mathrm{LND}, \text { cut off } 0.09 \\
\text { (Suggested LND } \\
\text { has limited value) }\end{array}$ \\
\hline Imre et al., 2016 & Retrospective & $\begin{array}{l}\text { Total: } 289 \\
\mathrm{~N}+: 101\end{array}$ & $\begin{array}{l}\text { OS } \\
\text { DFS }\end{array}$ & $\begin{array}{l}* \text { LND } \\
* \text { No of +ve LNs } \\
* \text { pN for OS but not DFS }\end{array}$ & $*$ LND only, cut off 0.09 \\
\hline Petrarolha et al., 2020 & Retrospective & $\begin{array}{l}\text { Total: } 186 \\
\text { N+: } 84\end{array}$ & $\begin{array}{l}\text { OS } \\
\text { DFS }\end{array}$ & $\begin{array}{l}\text { *LND } \\
\text { *Presence of +ve LNs } \\
\text { *Extracapsular extension } \\
\text { *+ve margins } \\
\text { *Lymphovascular invasion } \\
\text { *Perineural invasion for } \\
\text { OS but not DFS } \\
\text { *Smoking for DFS but not } \\
\text { OS }\end{array}$ & $\begin{array}{l}* \text { LND, cut off } 0.06 \\
* \text { Extracapsular } \\
\text { extension } \\
\text { *Smoking for DFS } \\
\text { but not OS } \\
\text { *Perineural } \\
\text { invasion for OS but } \\
\text { not DFS }\end{array}$ \\
\hline
\end{tabular}


In this study; LND, number of positive LNs, involved surgical margins, adjuvant chemoradiation and presence of metastatic LNs were the statistically significant predictors for disease recurrence in univariate analysis. LND remained the only significant independent factor for disease recurrence in $\mathrm{pN}+$ patients in multivariate analysis. LND was statistically significant predictor of overall treatment failure and nodal recurrence, however had no significant relation with local recurrence alone. Best LND cut off value to classify patients into high and low risk for recurrence was calculated to be 0.066 . For patients with LND > 0.066, HR for overall disease recurrence was 3.887 $(P=0.021)$, while HR for nodal recurrence was 6.453 $(P=0.008)$.

LND is believed to be superior to number of metastatic LNs as predictor for prognosis of laryngeal cancer. It includes not only the magnitude of LN metastasis but also the extent of nodal dissection with subsequent possible effect on prognosis. By evaluating the total number of LNs removed during surgery beside the number of positive LNs, the ratio compensates for the possible bias for number of positive LNs with limited neck dissection. Many studies have shown LND to be better prognostic factor than pathologic nodal staging and number of positive LNs in other types of cancers like oral cavity and urinary bladder cancers $^{[14,15]}$. LND has some limitations. Its value is affected by the magnitude of neck dissection and the pathology technique used, which may include more sensitive methods like serial sectioning or PCR. A minimum number of removed LNs needs to be determined to define the procedure as neck dissection and rely on LND. The seventh edition of the AJCC Cancer Staging Manual stated that: "A selective neck dissection will ordinarily include six or more lymph nodes and a radical or modified radical neck dissection will ordinarily include 10 or more lymph nodes." However, reported numbers of LN yield vary greatly between different reports ${ }^{[16,17]}$.

Limitations of our study include our limited number of patients, being done in one institution and relatively short follow up interval. Future studies including more number of patients with longer follow up, and in multiple institutions with multiple operators for neck dissection and different pathologists are needed to further validate the effect of LND on prognosis of patients with advanced laryngeal carcinoma, and better determine the best LND cut offs to categorize patients into high and low risk groups, for its use complementary to the conventional TNM classification for decision making regarding operative and postoperative treatment of patients with advanced laryngeal cancer.

\section{CONCLUSION}

Lymph node density (LND) was the only independent predictor for disease recurrence in $\mathrm{pN}+$ laryngeal cancer in our study. With LND $>0.066$, HR for disease recurrence was $3.887(P=0.021)$, and for nodal recurrence was $6.453(P=0.008)$. We also confirmed that presence of positive LNs nearly doubles the recurrence rate compared to N0 tumors in patients with advanced laryngeal SCC. However, with metastatic cervical LNs, pathologic nodal stage does not necessarily predict prognosis. LND should be used complementary to the conventional TNM staging to assess the precise risk of treatment failure and planning of possible postoperative adjuvant treatment.

\section{CONFLICT OF INTEREST}

There are no conflicts of interest.

\section{REFERENCES}

1. Jemal A, Bray F, Center MM, Ferlay J, Ward E, Forman D. Global cancer statistics. CA: a cancer journal for clinicians. 2011 Mar;61(2):69-90.

2. Papadas TA, Alexopoulos EC, Mallis A, Jelastopulu E, Mastronikolis NS, Goumas P. Survival after laryngectomy: a review of 133 patients with laryngeal carcinoma. European Archives of Oto-RhinoLaryngology. 2010 Jul 1;267(7):1095-101.

3. Ryu IS, Roh JL, Cho KJ, Choi SH, Nam SY, Kim SY. Lymph node density as an independent predictor of cancer-specific mortality in patients with lymph nodepositive laryngeal squamous cell carcinoma after laryngectomy. Head \& neck. 2015 Sep;37(9):1319-25.

4. Wang YL, Li DS, Wang Y, Wang ZY, Ji QH. Lymph node ratio for postoperative staging of laryngeal squamous cell carcinoma with lymph node metastasis. PloS one. 2014 Jan 27;9(1):e87037.

5. Künzel J, Mantsopoulos K, Psychogios G, Agaimy A, Grundtner P, Koch M, Iro H. Lymph node ratio is of limited value for the decision-making process in the treatment of patients with laryngeal cancer. European Archives of Oto-Rhino-Laryngology. 2015 Feb 1;272(2):453-61.

6. Imre A, Pinar E, Dincer E, Ozkul Y, Aslan H, Songu M, Tatar B, Onur I, Ozturkcan S, Aladag I. Lymph node density in node-positive laryngeal carcinoma: analysis of prognostic value for survival. OtolaryngologyHead and Neck Surgery. 2016 Nov;155(5):797-804. 
7. Petrarolha S, Dedivitis R, Matos L, Ramos D, Kulcsar M. Lymph node density as a predictive factor for worse outcomes in laryngeal cancer. European Archives of Oto-Rhino-Laryngology. 2020 Mar;277(3):833-40.

8. Ritoe SC, Bergman H, Krabbe PF, Kaanders JH, van den Hoogen FJ, Verbeek AL, Marres HA. Cancer recurrence after total laryngectomy: treatment options, survival, and complications. Head \& Neck: Journal for the Sciences and Specialties of the Head and Neck. 2006 May;28(5):383-8.

9. Jones TM, De M, Foran B, Harrington K, Mortimore S. Laryngeal cancer: United Kingdom national multidisciplinary guidelines. The Journal of Laryngology \& Otology. 2016 May;130(S2):S75-82.

10. Pfister DG, Laurie SA, Weinstein GS, Mendenhall WM, Adelstein DJ, Ang KK, Clayman GL, Fisher SG, Forastiere AA, Harrison LB, Lefebvre JL. American Society of Clinical Oncology clinical practice guideline for the use of larynx-preservation strategies in the treatment of laryngeal cancer. Journal of clinical Oncology. 2006 Aug 1;24(22):3693-704.

11. Ho AS, Kim S, Tighiouart M, Gudino C, Mita A, Scher KS, Laury A, Prasad R, Shiao SL, Ali N, Patio C. Association of quantitative metastatic lymph node burden with survival in hypopharyngeal and laryngeal cancer. JAMA oncology. 2018 Jul 1;4(7):985-9.

12. Kalnins IK, Leonard AG, Sako K, Razack MS, Shedd DP. Correlation between prognosis and degree of lymph node involvement in carcinoma of the oral cavity. The American Journal of Surgery. 1977 Oct $1 ; 134(4): 450-4$
13. Bernier J, Cooper JS, Pajak TF, Van Glabbeke M, Bourhis J, Forastiere A, Ozsahin EM, Jacobs JR, Jassem J, Ang KK, Lefèbvre JL. Defining risk levels in locally advanced head and neck cancers: a comparative analysis of concurrent postoperative radiation plus chemotherapy trials of the EORTC (\# 22931) and RTOG (\# 9501). Head \& Neck: Journal for the Sciences and Specialties of the Head and Neck. 2005 Oct;27(10):843-50.

14. Kim SY, Nam SY, Choi SH, Cho KJ, Roh JL. Prognostic value of lymph node density in node-positive patients with oral squamous cell carcinoma. Annals of surgical oncology. 2011 Aug 1;18(8):2310-7.

15. Gil Z, Carlson DL, Boyle JO, Kraus DH, Shah JP, Shaha AR, Singh B, Wong RJ, Patel SG. Lymph node density is a significant predictor of outcome in patients with oral cancer. Cancer: Interdisciplinary International Journal of the American Cancer Society. 2009 Dec 15;115(24):5700-10.

16. Patel SG, Amit M, Yen TC, Liao CT, Chaturvedi P, Agarwal JP, Kowalski LP, Ebrahimi A, Clark JR, Cernea CR, Brandao SJ. Lymph node density in oral cavity cancer: results of the International Consortium for Outcomes Research. British journal of cancer. 2013 Oct;109(8):2087-95.

17. Edge SB, Byrd DR, Carducci MA, Compton CC, Fritz AG, Greene FL. AJCC cancer staging manual. $7^{\text {th }}$ edition. New York: Springer; 2010:57-88. 